\title{
Application of PBL Teaching Method in the Course of Digital Products Inspection
}

\author{
Ping Peng \\ Institute of Finance and Economics \\ Guangdong University of Science and Technology, \\ 523083 Dongguan, Guangdong, China \\ E-mail: 397065001@qq.com
}

\begin{abstract}
As a group selection course of international Economics and Trade, digital products inspection course has a certain influence on students' theoretical knowledge and practical business ability of digital product trade. Based on practical teaching on digital products inspection course of the international Economics and Trade, which is a key subject in Guangdong University of Science and Technology, this paper discusses the application and influence of PBL teaching method.
\end{abstract}

Keywords: PBL teaching method; Digital products; Digital products inspection

\section{INTRODUCTION}

The entry-exit inspection course is an indispensable part of international trade practice, especially the fulfillment of foreign trade order. The entry and exit inspection course is a core curriculum, which combinates of international trade professional knowledge and the skill of vocational ability. The entry and exit quarantine practice courses are adapt to the needs of the development of the current international trade in China, also meet the national requirements on entry and exit of goods.

Guangdong university of science and technology is an application-oriented undergraduate college. Here inspection courses have been divided into two directions: clothing inspection and digital products inspection of the international economic and trade major, which is based on the needs of application-oriented personnel training programs. Besides, there is no textbook focusing on digital products inspection. The existing textbooks mainly compile the policies of the entry-exit inspection and quarantine of the country, and do not research how to meet the actual demand of the enterprises. It is difficult to teach the necessary inspection knowledge, also to master the relevant inspection skills.

Therefore, the PBL teaching method is fully utilized in the process of teaching the project according to the practice of the company's inspector, assigning tasks to the project and providing knowledge support for the task.

It is in line with the purpose of students' ability of international economic and trade major, and it is more in line with the professional standards and ability requirements of foreign trade enterprises to apply for inspection positions, so that students can better coordinate with foreign trade enterprises after graduation.

\author{
Hulin Zhai \\ Institute of Management \\ Guangdong University of Science and Technology, \\ 523083 Dongguan, Guangdong, China \\ E-mail: 494312664@qq.com
}

\section{OVERVIEW OF PBL TEACHING METHOD}

Problem-based learning, or PBL, is a problem-oriented, student-centered teaching method. It has been proposed by Barrows, a professor of neurology at the university of McMaster in Canada in 1969, has become an internationally popular teaching method with a wide range of applications from the world's top universities such as Maastricht university.

The important difference between PBL and traditional teaching methods is that traditional teaching attaches more importance to teaching, and teachers teach mainly in 45 minutes of class, meanwhile students are passive.

And PBL teaching method makes the role of the students' learning from passive to active, through the problem of guidance, initiative to collect data, analyzing problems, putting forward the method to solve problems, the problem feedback, and so on, arises students' interest in study, fully mobilizes students' learning initiative, trains students the ability to solve the problem. Those will deepen the effect on teaching and learning.

\section{REQUIREMENTS OF DIGITAL PRODUCTS INSPECTION COURSE}

Usually "digital" refers to digital products that contain "digital technology" such as digital cameras, digital learning machines, digital walkman and so on. Digital identification products have come to the fore, with the development of science and technology, replacing the traditional film, video, audio, etc. These are collectively referred to as digital products. Television, communications equipment, mobile or portable electronic tools, for example, have been digitized to a considerable degree. So digital products can be defined as: MP3, U disk, smart phones, digital camera, video camera, scanner, smart wear and so on, which can be operated by digital and coding machine and can be connected to the computer.

Students are required to master the basic requirements of process in digital products entry and exit inspection, on the basis of understanding the entry-exit inspection and the entry and exit commodity catalogue for inspection and quarantine by the entry-exit inspection and quarantine organ, in digital products inspection course.

PBL teaching method is always used in teaching practice. For example, firstly teachers set the small section scene, then students are divided into groups, and complete the discussion in the whole process of digital products 
inspection course, in order to seize the students' learning interest and enthusiasm, test the teaching effect.

\section{APPLICATION OF PBL IN DIGITAL PRODUCT INSPECTION COURSE}

Using PBL teaching method, teachers are required to be acquainted with not only the knowledge about the international economy and trade, but also digital products inspection course. It needs to proposes the question, analyze problems, organize and manage the class, for teachers.

In digital products inspection course, we follow the process: propose the question by teachers - check data by students- discuss in group- show results - review by teachers. This paper analyzes the application of PBL in classroom teaching by taking the scope of entry-exit inspection.

\section{A. Teaching Preparation}

Teachers need to be familiar with the syllabus and students' abilities, so as to plan the key points and difficulties of learning. Choose the appropriate situation to stimulate students' interest in active learning; Make a targeted discussion outline, choose the problem which is suitable for each class to master the specific situation, teach students in accordance of their aptitude.

\section{B. Teaching basic Knowledge}

According to the teaching goal, first, teachers should explain comprehensive, system, detail the related theory knowledge such as the entry-exit inspection, the development, basic structure and query methods of the entry and exit commodity catalogue for inspection and quarantine by the entry-exit inspection and quarantine organ, using PBL teaching method, for making the students learn better and more comprehensive acquired knowledge. What needs to be noticed here is to get the students to understand what their task is and to answer their questions with specific answers.

\section{Setting up the Teaching Situation}

Teachers need to focus in accordance with the students to set up the corresponding situation. This section has played a decisive role, it also requires teachers to understand the social hot spots, grasp student's psychology. According to the gender difference between male and female, the demand for digital products is slightly different Here we choose nikon digital camera and huawei mobile phone as the material. Specifically, students act as importers and exporters, and import and export these two commodities.

\section{Asking Questions}

Questions should be difficult to degree based on different class learning habits. If the problem is too simple, students will quickly give a solution, that can't make proud to realize the depth of knowledge extension. At the same time, it is not too difficult to design. Students may withdraw or even give up trying. Therefore, in combination with the above situation, the question is raised: how to report the two products, which are imported and exported by a foreign trade company in Dong guan.

\section{E. Analyzing the Problem}

The students were divided into groups according to the conditions given by the teacher. Each group of students is made up 5-6 people. The division is resolved within each group. Each group needs to select the team leader, the narrators of the exhibition, the foreign trade company's inspection staff, the import and export inspection and quarantine bureau related staff and other roles. The groups analyze and discuss the role positioning, the problems on their own, and could find relevant information by all means. The teachers in this section need timely guidance.

\section{F. Solving Problems}

After the analysis and discussion, each group member states their own opinions according to their own roles. This process is led by the team leader to guide each team member's opinion expression and group discussion. The final group accomplishes a complete solution together.

\section{G. Results Show}

The speaker of each group is asked to stand on the front of the platform to display the group's inspection procedures. Each group is presented with the help of multimedia teaching tools, such as PPT for intuitive and effective explanation. Then the other groups ask questions and the showing group solutes. Finally, teachers will ask questions, bring comment and suggestions for improvement. The presentation group combines the discussion with the students and the teacher to improve and enrich their solution.

\section{H. Assessment Score}

The starting point of the PBL teaching method is to realize students' independent study. The evaluation scores include self-evaluation, group evaluation and teacher rating, respectively, accounting for the proportion of three-three-four. That is, the first two items account for 30\% of the total score respectively, and the teacher rating score $40 \%$. Criteria include: preparation, solution of rationality, whether to do their job, the quality of showtime, speaker's statement of in-game adjustments ability, answers to questions from the group's members, etc.

\section{SUMMARY}

International economic and trade major committed to the training students who is able to work in a multinational company, foreign economic and trade sector, foreign companies and government agencies engaged in business, management, policy research. PBL teaching method applied in the digital products inspection course, can not only create a relaxed, active learning atmosphere, so that the students can speak actively and freely, express own viewpoint fully, get information from other students and teachers easily. At the same time, the question on digital products inspection as much as possible is showed out. These will deepen the understanding in the discussion, make the learning process shorter and more impressive, also exercise the students ability in many aspects, such as the ability of literature search, data access generalizations, 
comprehensive understanding ability, oral expression ability, and the ability of lifelong learning, etc., which will lay a good foundation for future work.

\section{ACKNOWLEDGMENT}

Fund: Pilot project of professional comprehensive reform in Guangdong University of Science and Technology [2015]48. (1501001)

\section{REFERENCES}

[1] Lang Liu. Application of PBL Teaching Method in the Teaching of Medical Advanced Mathematics [A]. Wuhan Zhicheng Times Cultural Development Co., Ltd.Proceedings of 2017 International Conference on Innovations in Economic Management and Social Science (IEMSS 2017) [C].Wuhan Zhicheng Times Cultural Development Co., Ltd:,2017:7.

[2] Xie Jin. Research on the Application of PBL in Curriculum Designing of Application-oriented Universities [A]. Information Technology \& Industrial Engineering Research Center.Results of 2016 International Conference on Education Innovation and Practice (Education Innovation and Practice Volume II) [C] Information Technology \& Industrial Engineering Research Center, 2016:7.

[3] Ying-ling SHI. What Kind of Role does the Teacher Play in Problem Based Learning (PBL)? [A]. Science and Engineering Research Center.Proceedings of 2016 3rd International Conference on Education Reform and Modern Management (ERMM 2016) [C].Science and Engineering Research Center:,2016:5.

[4] Robert F. Banks, Jordi Tiana-Alsina, José María Baldasano, Francesc Rocadenbosch, Alexandros Papayannis,Stavros Solomos, Chris G. Tzanis. Sensitivity of boundary-layer variables to PBL schemes in the WRF model based on surface meteorological observations, lidar, and radiosondes during the HygrA-CD campaign [J]. Atmospheric Research, 2016, 176-177.

[5] Jingjing Liu, Jianping Huang, Bin Chen, Tian Zhou, Hongru Yan, Hongchun Jin, Zhongwei Huang, Beidou Zhang. Comparisons of PBL heights derived from CALIPSO and ECMWF reanalysis data over China [J]. Journal of Quantitative Spectroscopy and Radiative Transfer,2015,153.

[6] Matthew Choon-Eng Gwee. Globalization of Problem-based Learning (PBL): Cross-cultural Implications [J]. Kaohsiung Journal of Medical Sciences, 2008,24(3)

[7] Youngseob Kim,Karine Sartelet,Jean-Christophe Raut,Patrick Chazette. Influence of an urban canopy model and PBL schemes on vertical mixing for air quality modeling over Greater Paris $[\mathrm{J}]$. Atmospheric Environment, 2015,107.

[8] Jiqin Lian, Fengtian He. Improved performance of students instructed in a hybrid PBL format $[\mathrm{J}]$. Biochemistry and Molecular Biology Education,2013,41(1).

[9] M. Heijne-Penninga, J. B. M. Kuks,W. H. A. Hofman,A. M. M. Muijtjens,J. Cohen-Schotanus. Influence of PBL with open-book tests on knowledge retention measured with progress tests[J]. Advances in Health Sciences Education, 2013, 18(3). 